\title{
AUTOMATED DATA PROCESSING SYSTEM FOR OSCILLOSCOPE MEASUREMENTS DURING AN ENVIRONMENTAL TEST
}

\author{
Sergey Shmakov ${ }^{1, *}$, Maxim Cherniak $^{2}$, Anna Boruzdina ${ }^{2}$, Peter Skorobogatov ${ }^{2}$, \\ Alexander Nikiforov ${ }^{2}$ \\ ${ }^{1}$ JSC "Specialized Electronic Systems", 115409, Moscow, Russia \\ ${ }^{2}$ National Research Nuclear University MEPhI (Moscow Engineering Physics Institute), 115409, \\ Moscow, Russia
}

\begin{abstract}
The paper discusses the automation of the processing of images obtained with an oscilloscope using National Instruments LabVIEW software. The mathematical background is presented as well as standard hardware communication interface. The block diagram of the electrical signal acquisition and processing system and the front panel with an example of processed waveforms is shown in the paper.
\end{abstract}

\section{Introduction}

The calibration process is an integral part of an environmental test using laser techniques to model the destabilizing effects on a device [1-3]. The main objective of the calibration process is a determination of the calibration factor. The calibration factor is determined by comparison of the dependences of the reaction of the device under the external influence and a laser source in pulse mode. One of the problems encountered during the work with external influence sources is interference signals. Hence, there is a need for software processing of the information received from the measurement equipment $[4,5]$. In particular, the challenge is to create the software allowing to determine the integral from the waveform (the area under the curve), since the integral of the interference is significantly smaller than that of the useful signal. It is also necessary to automate the process of determining the minimum and maximum of the test signal during the laser testing. Ease data collection and processing based on existing test systems are required as well. It is necessary to ensure the ability to save the information in a convenient form for further work.

\section{Hardware and software}

Operating mode of the chip during the environmental test is set using a PXI platform based on the NI PXI-1033 chassis. This platform includes NI PXI-7951R FPGA module with NI $6581 \mathrm{I} / \mathrm{O}$ adapter, NI PXI-4110 module as a voltage supply, and PXI-4070 digital multimeter for control of the current consumption.

\footnotetext{
* Corresponding author: sbshmak@spels.ru
} 
The software for interfacing Tektronix TDS 2024B oscilloscope with a computer and further data processing was implemented in NI LabVIEW programming environment with NI-VISA module.

\section{Description of the solution}

Block diagram of the system for collecting and processing electrical signals is shown in Figure 1.

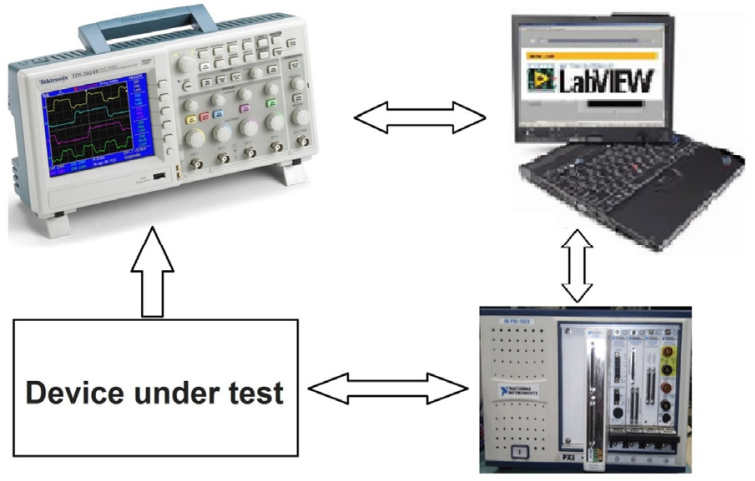

Figure 1. Block diagram of the system for collecting and processing electrical signals.

During the experiment, PXI-7951 FPGA module with NI 6581 adapter and PXI-4110 supply module set the control signals and bias of the DUT respectively. Oscilloscope measured the parameters of the output signals.

Test signals are inputted to an analog oscilloscope and a one-dimensional array of digital data is transmitted to a computer using USB interface.

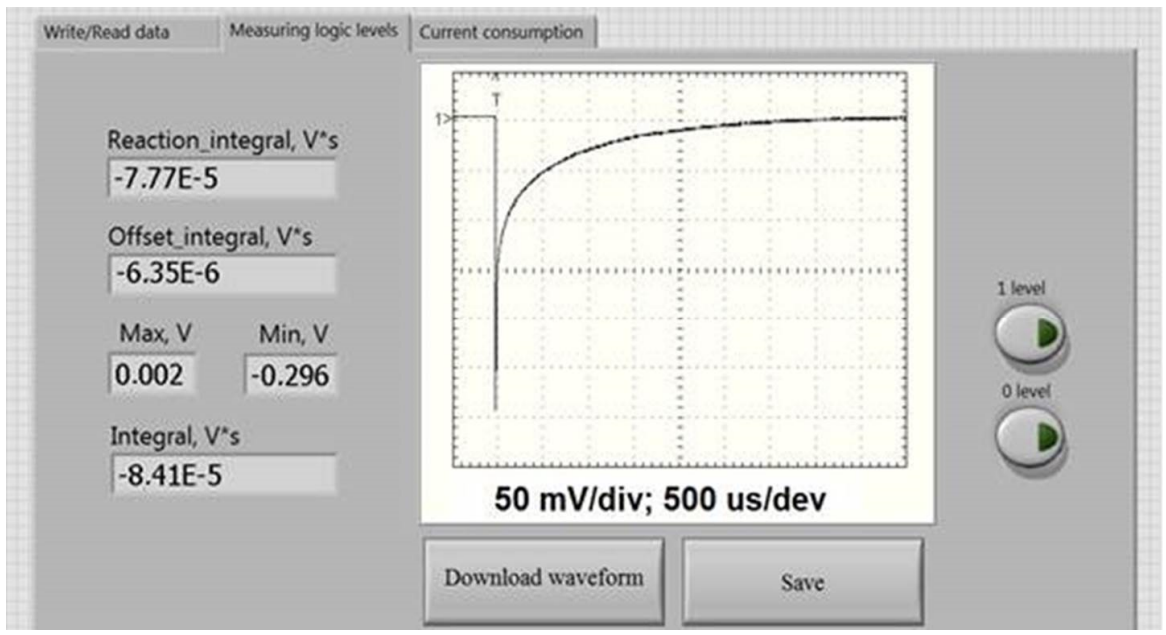

Figure 2. The front panel of the virtual instrument. Offset Integral is a constant component, Reaction Integral is the total integral, Integral is the total integral with DC component subtracted, Min - the minimum value of the signal on the waveform, Max - the maximum value of the signal on the waveform.

The array has a capacity of 2500 elements and contains the signal digitized by the oscilloscope in ADC units. Each element of the array contains the result of digitizing by 8 
bit $\mathrm{ADC}$ in a form of an integer number. Values fall in a range from -127 to 128 . To determine the transformation coefficient of ADC conversion units the expression (1) is applied in Volts. $N$ - the number of cell divisions the oscilloscope grid; $D$ - vertical division of the oscilloscope

$$
K=N \cdot D / 256
$$

The minimum and the maximum value are determined by the oscilloscope and obtained by the program from Meas 1 and Meas 2 registers.

Integral calculation program performs the summation of all the data from an array of post-trigger, which were multiplied by the corresponding values of the scale factor sweep oscilloscope. If there is a constant component available in the signal, it will be taken into account in the final result (2).

$$
\text { Integral }=\text { Reaction_integral }- \text { Offset_integral }
$$

The constant component is calculated by the method indicated above, but 250 array elements are taken before trigger point, that is, until the arrival of the signal, which is multiplied by a constant equal to N/250 where $N$ - number of elements in the array after the trigger. The Figure 2 shows the front panel of the program.

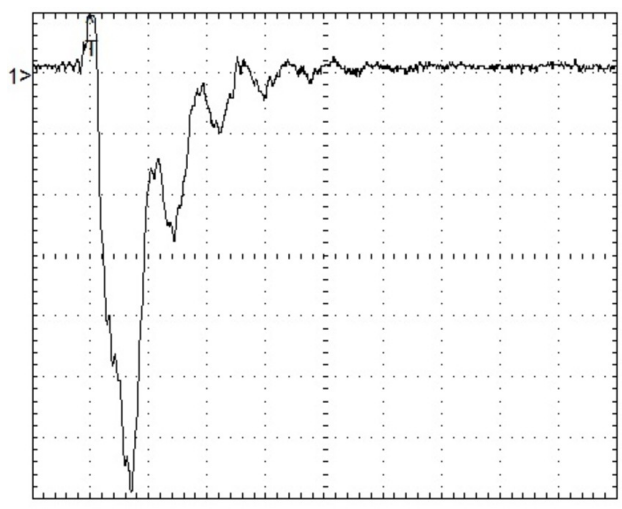

$20 \mathrm{mV} / \mathrm{div} ; 50 \mathrm{~ns} / \mathrm{div}$

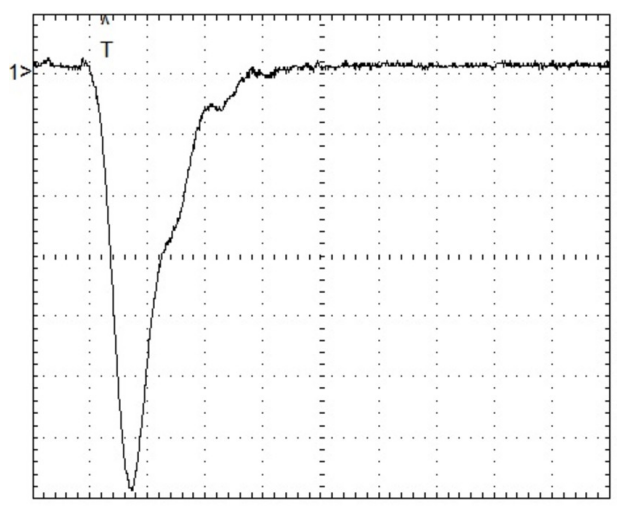

$20 \mathrm{mV} / \mathrm{div} ; 50 \mathrm{~ns} / \mathrm{div}$

Figure 3. Typical reaction during calibration: $a$ - External influence; $b$ - Laser light source. 


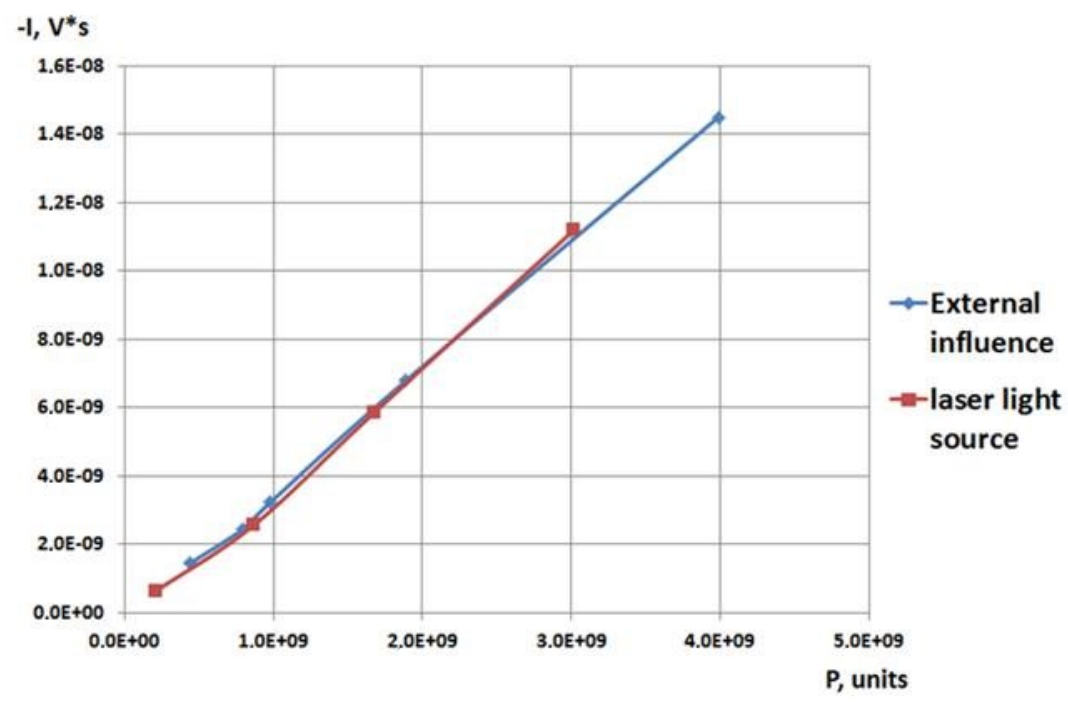

Figure 4. Combined charts based on the calibration coefficient obtained using the developed software.

The program allows the waveform to be saved as a png file (Figure 3), and, as seen on Figure 2, can be easily integrated as a functional unit of the test system [6-12], and allows us to work with the oscilloscope remotely, if necessary [13].

The possibility of remotely work is provided by sending to the oscilloscope commands such as $\mathrm{CH}<\mathrm{x}>$ :SCAle $<$ NR3 $>$ (set scale-division value), MEASU:MEAS1:VALue? (check the scale-division value), HORizontal:MAIn:POSition? (check the position of the start of the trigger), HORizontal:MAIn:POSition $<$ NR3 $>$ (set the position of the beginning of the trigger) via NI-VISA driver.

Using the developed software, graphs shown in Figure 4 were obtained and matched using the calibration factor. During an environmental test, this software is useful for monitoring parameters such as output voltage drop at logical zero and logical one (Figure 5), the pulse response of current consumption.

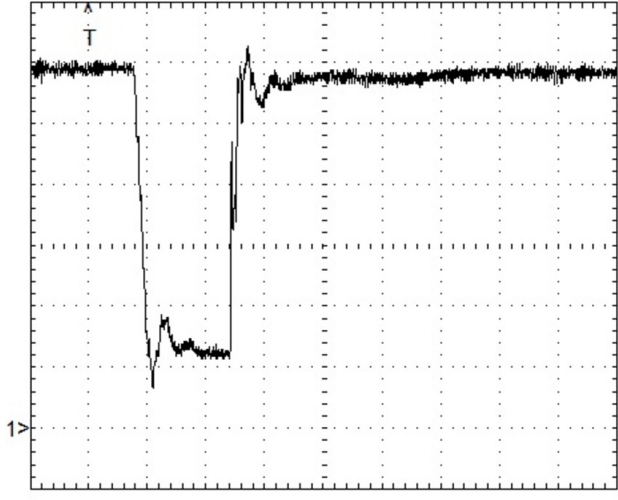

$0.5 \mathrm{~V} / \mathrm{div} ; 250 \mathrm{~ns} / \mathrm{div}$

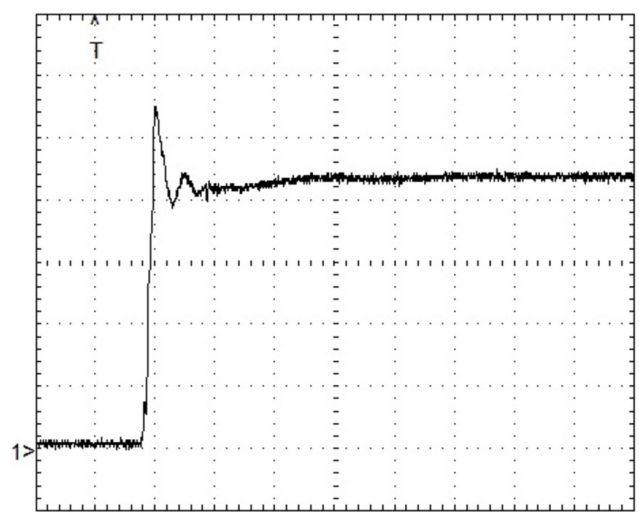

$1 \mathrm{~V} / \mathrm{div} ; 250 \mathrm{~ns} / \mathrm{div}$

Figure 5. Typical reaction: $a$ - Waveform obtained to monitor the output high logic level; $b$-Waveform obtained for low logic level control (switch from the low logic level to a high logic level). 


\section{Implementation and its prospects}

The developed software is successfully implemented and used in JSC "ENGOs SPELS" as a signal processing system with Tektronix TDS 2024B oscilloscope.

Improvement of software for measurement dynamic characteristics is planned, such as data access time (time elapsed since an enable signal and the output lines to establish relevant data), the rise time and fall time of the signal, control of the frequency of the output signals.

\section{Conclusions}

Thus, system is developed for collecting and processing electrical signals and allowing to determine the integral from the waveform of the signal under examination and to determine the maximum and minimum value. Developed software gives the opportunity to save measured waveforms in .png file format, is compatible with already existing test facilities and can be used as a separate functional block. One should notice that developed software allows controlling the oscilloscope remotely; this fact is of particularly importance when working on test facilities.

\section{Acknowledgments}

The work performed under grant agreement between the Russian Ministry of Education and the National Research Nuclear University MEPhI on November 24, 2014 № 14.578.21.0075 (unique identifier RFMEFI57814X0075 for Applied Scientific Research).

\section{References}

[1] P. K. Skorobogatov, A. Y. Nikiforov, A.N. Egorov, Russian Microelectronics 44, 8 (2015) doi: 10.1134/S1063739715010084

[2] A.Y. Nikiforov, P. K. Skorobogatov, Russian Microelectronics 35, 138 (2006) doi: $10.1134 / \mathrm{S} 1063739706030024$

[3] A.N. Egorov, A.I. Chumakov, O.B. Mavritsky, A. A.Pechenkin, D. V. Savchenkov, V. A. Telets, A. V.Yanenko, IEEE Radiation Effects Data Workshop 2015-January , 7004570 (2016) doi:10.1109/REDW.2014.7004570

[4] W. Fan, Y. An, D. Liu and S. Guan, MATEC Web of Conferences 40, 07002 (2016) doi: 10.1051/matecconf/20164007002

[5] X.Tan, MATEC Web of Conferences 31, 09003 (2015) doi: $10.1051 /$ matecconf $/ 20153109003$

[6] M. P. Belova, D. V. Pechenkina, A. Y. Borisov, L. N. Kessarinskiy, D.V. Boychenko, 2015 International Siberian Conference on Control and Communications (SIBCON), 7146995 (2015) doi: 10.1109/SIBCON.2015.7146995

[7] A. B. Boruzdina, A. A. Orlov, A. V. Ulanova, N. G. Grigor'ev, A.Y. Nikiforov, 2015 International Siberian Conference on Control and Communications (SIBCON), 7147007 (2015) doi: 10.1109/SIBCON.2015.7147007

[8] A.V. Demidova, A. Y. Borisov, L. N. Kessarinskiy, D.V. Boychenko, 2015 International Siberian Conference on Control and Communications (SIBCON), 7147036 (2015) doi: 10.1109/SIBCON.2015.7147036

[9] M.E. Cherniak , A.V. Ulanova, A.Y. Nikiforov, Proceedings of the International $\begin{array}{llll}\text { Conference on } & \text { Microelectronics } & \text { (ICM), } 6842119 & \text { (2014) }\end{array}$ doi: 10.1109/MIEL.2014.6842119 
[10] I. I. Shvetsov-Shilovskiy, P.V. Nekrasov, A.V. Ulanova, A. A.Smolin, A. V. Sogoyan, 2015 International Siberian Conference on Control and Communications (SIBCON), 7147282 (2015) doi: 10.1109/SIBCON.2015.7147282

[11] I. O. Loskutov, A. B. Karakozov, P.V. Nekrasov, A.Y. Nikiforov, 2015 International Siberian Conference on Control and Communications (SIBCON), 7147128 (2015) doi: 10.1109/SIBCON.2015.7147128

[12] G. G. Davydov, A. S. Kolosova, L. N. Kessarinskiy, D.V. Boychenko, 2015 International Siberian Conference on Control and Communications (SIBCON), 7147094 (2015) doi: 10.1109/SIBCON.2015.7147094

[13] A.S. Artamonov, A.A. Sangalov, A.Y. Nikiforov, V. A. Telets, D.V. Boychenko, IEEE Radiation Effects Data Workshop, $7004600 \quad$ (2014) doi: 10.1109/REDW.2014.7004600 